\title{
Erratum to: Modeling of the Equiaxed Dendrite Coarsening Based on the Interdendritic Liquid Permeability during Alloy Solidification
}

\author{
S.M.H. MIRBAGHERI
}

DOI: $10.1007 /$ s 11663-009-9325-0

(C) The Minerals, Metals \& Materials Society and ASM International 2009

\section{ERRATUM TO: METALLURGICAL AND MATERIALS TRANSACTIONS 39B (2008) 469-483 DOI 10.1007/S11663-008-9149-3}

THE author has found errors in figures 12, 13, and 14 of this manuscript. The correct figures follow:

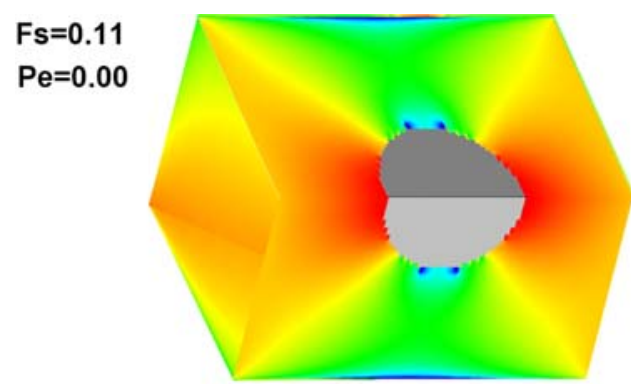

(a)

$\mathrm{Fs}=0.11$

$\mathrm{Pe}=0.33$

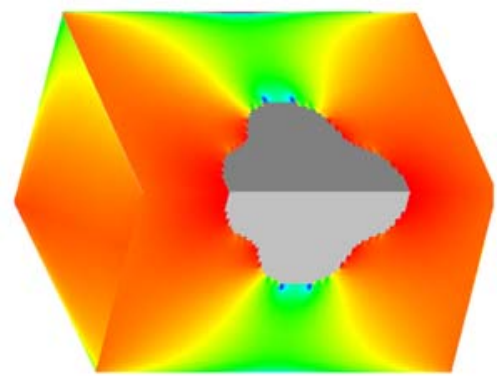

(b)

$\mathrm{Fs}=0.11$

$\mathrm{Pe}=\mathbf{0 . 5 0}$

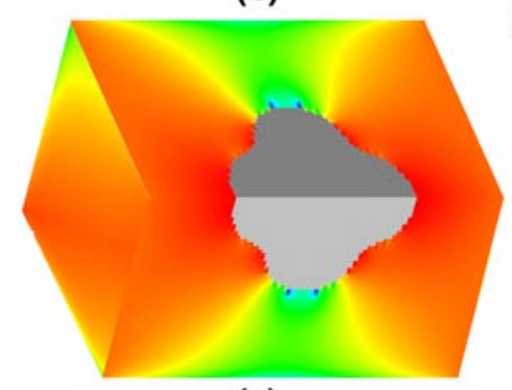

(c)

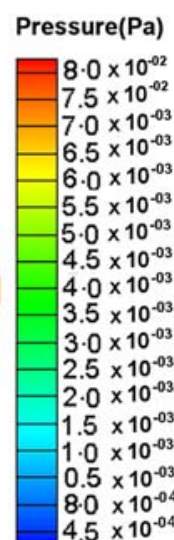

Fig. 12-Isopressure field simulation for the $\mathrm{Pb}-35$ wt pct $\mathrm{Sn}$ dendrite at different perturbations for solid fractions of 0.11 .
S.M.H. MIRBAGHERI, Assistant Professor, is with the Department of Mining and Metallurgical Engineering, Amirkabir University of Technology, Tehran, Iran. Contact e-mail: smhmirbagheri@aut. ac.ir

The online version of the original article can be found under doi: 10.1007/s11663-008-9149-3.

Article published online December 2, 2009. 
$\mathrm{Fs}=0.18$

$\mathrm{Pe}=0.00$

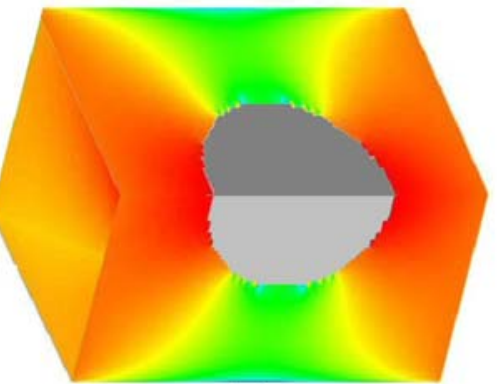

(a)

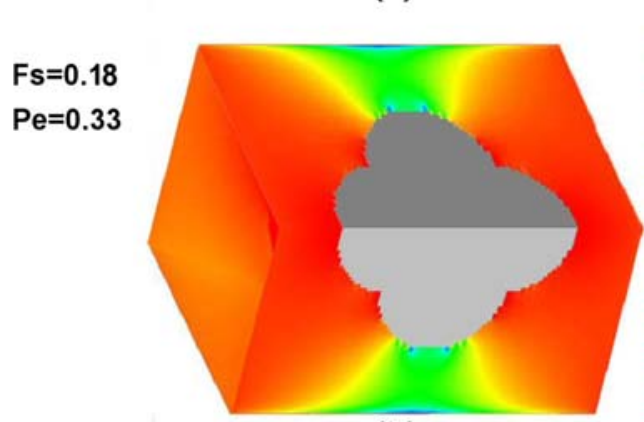

(b)

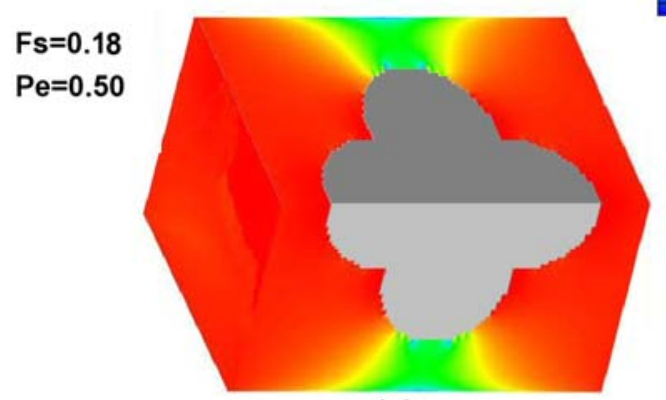

(c)

Fig. 13-Isopressure fields simulation for the $\mathrm{Pb}-35$ wt pct $\mathrm{Sn}$ dendrite at different perturbations for solid fractions of 0.18 .
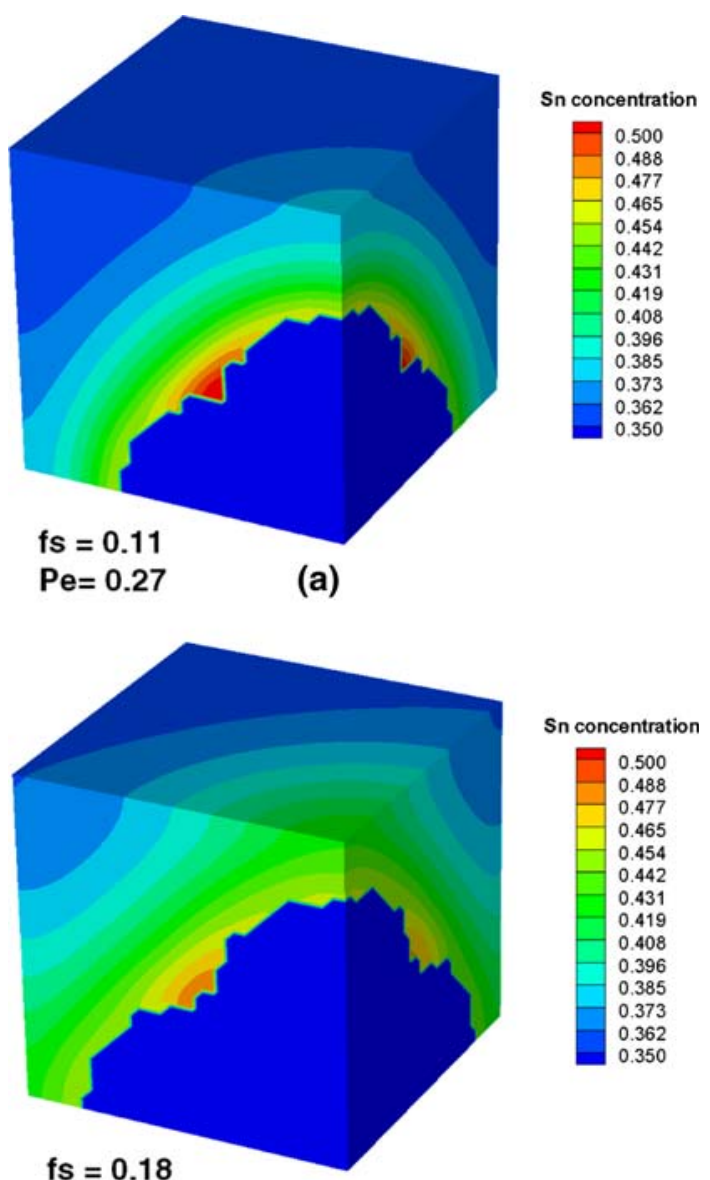

$\mathrm{Pe}=0.30$

(b)

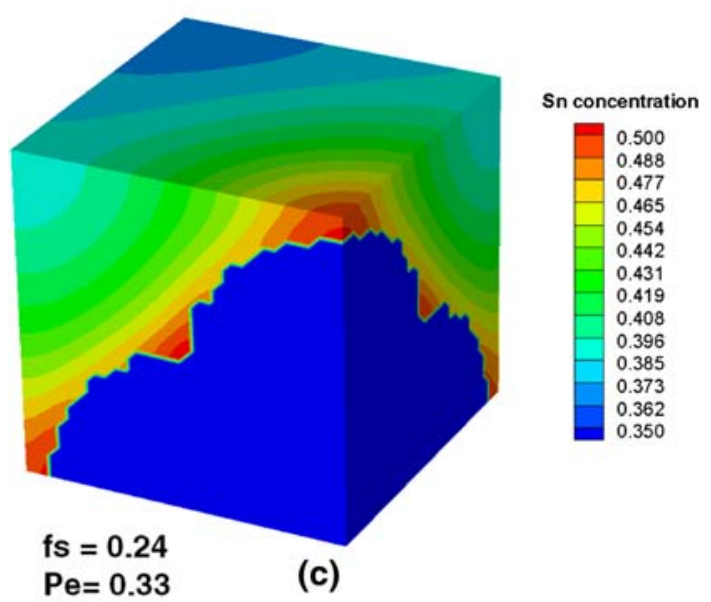

Fig. 14-Isoconcentration simulation results for $\mathrm{Pb}-35$ wt pct $\mathrm{Sn}$ dendrites at the solid fractions $0.11,0.18$, and 0.24 , respectively. 